\title{
Folliculitis Decalvans and Pyoderma Gangrenosum
}

Sudarshan LR , Jagat S P

\section{Folliculitis decalvans}

Types of alopecia commonly observed in our Skin OPD are Androgenic, telogen, anagen, drug induced, endocrinal, systemic disease, alopecia areata, tinea capitis, bacterial, discoid lupus erythematosus, lichen planus, pseudopelade.

Folliculitis decalvans is a rare chronic progressive follicular pustular eruption that results in cicatricial alopecia of scalp or other area.

It usually occurs in females of 30-60 years and after adolescence in males.

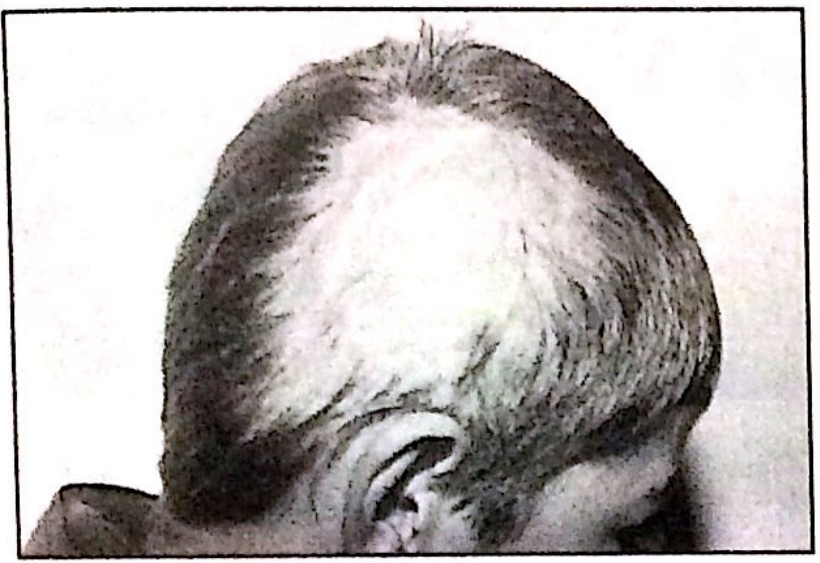

Figure 1: Alopecic patch $14 \mathrm{~cm} \mathrm{x} 10 \mathrm{~cm}$ right temporal region with one linear bulla on one side of periphery

\section{Case report}

A13 years old male child presented on 27 th December 2003 with painful patchy hairless area over scalp of 6 month duration patient gives history of excessive wetting of scalp every 20-30 days each lasting for a few days.

There is no family history of similar illness

Patient has not been on treatment so far.

Examination revealed erythematous oedematous alopecic area of $12 \times 10 \mathrm{~cm}$ on right temporal region.

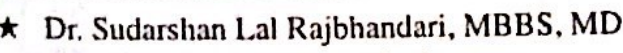
Col., Consultant Dermatologist

$\diamond$ Dr. Jagat Singh Pande, MBBS, MD Lt Col., Consultant Pathologist Shree Birendra Hospital, Chhauni
Surface at places show oozing. A linear bulla is seen at one side of periphery. Patch is tender, indurated and crusts felt. Other areas of scalp show severe seborrhoea.

\section{Biopsy finding}

Epidermis -- normal

Dermis -- sheets of lymphocytes, numerous plasma cells, a few macrophages, a few neutrophils and at places fibrosis in perifollicular areas in deep dermis consistent with folliculitis decalvans. No evidence of pseudopelade.

Sheets of, plasma cells, lymphocytes, a few neutrophils perifollicular region

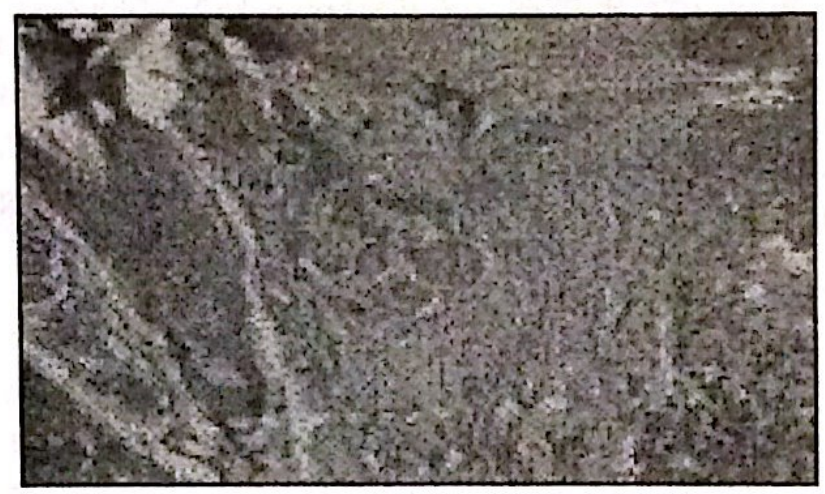

Figure 2: (Microphotograph showing Sheets of, plasma cells, lymphocytes, a few neutrophils at perifollicular region)

\section{Magnified view of perifollicular region}

Treatment patient was treated with topical mupirocin, ketoconazole shampoo, ceftriaxone axetil for 10 days, Rifampicin for 60 days. On August, after 4 months of completion of treatment patients father says patient has regrowth of hair. Again in 1st of Nov patient's father says he went home a few days ago and he shaved the affected area according to doctor's instruction and notices pitted scars $\mathrm{He}$ was cautioned as a part of 
counseling that the hair may restart falling and if so to inform the doctor at the earliest. Folliculitis decalvans is known to be recalcitrant to treatment.

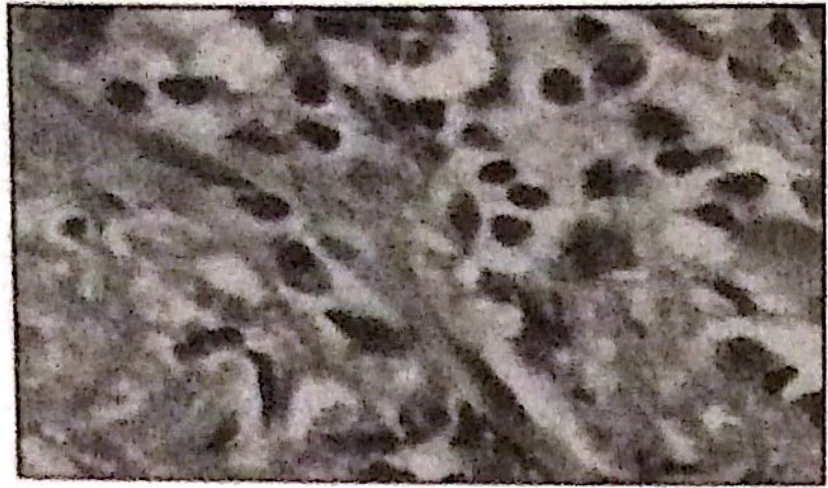

Figure 3: (Magnified view of perifollicular region)

\section{References}

1

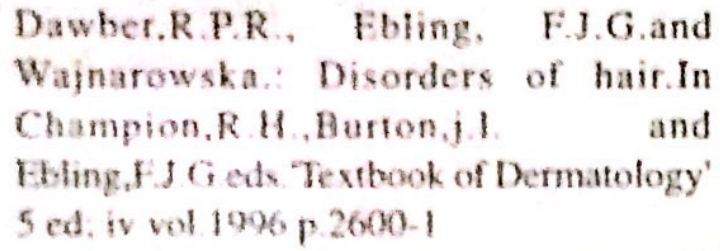

2. Wadhwa,S L., Khopker.U. and Mhaske, V: Hair and scalp disorders. In Valia.R.G. and Valia,A.R eds Textbook and Allas of Detmatology and edist vol. 2001 p.741. Bhalani Publishing House, Mumbai.

\section{Pyodema gangrenosum}

It wax firat described by Brunting and colleagues in 1930 is is a rare destructive. inflammatory, fecroin diondes of thin and presents with tender, erytoctuatous pustule taming to blue, black and then progresstucly enlarging nlect with undermined ratued fordere th nus remain single or develop in to mulaple testons mostly involving lower legs.

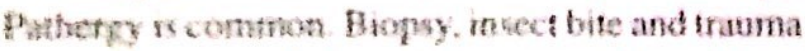
may induce new lestons. May occur idropathic of in assoctation with systemic diseases like inflammatory howel diseases, connective tissue discanes bepatic, fenal disorder, carcinoma, berkentia ete.

\section{Case report}

A 54 years old exserviceman from Pokhara presctited with progressively growing ulcers with servet haemorntagic discharges of 4 years duration on 2nd March 2004.
Initially patienthad leech bite at right ankle, out by the patient which caused developmes nonhealing ulcer. Similar lesions started appeat spontaneously at other sites like; dorsa both ankles, fingers, toes, legs, elbows, forea upperarms, scrotum and both pinna.

\section{Clinical findings}

Each ulcer had raised undermined border, surface was covered with serous or haemorrt crusts, base was indurated and tender. Ulcersy polysized, distributed over dorsa feet, ankles, lo legs, knees, elbows, pinna and scrotum

Pulp of the fingers and toes had pustules, dors feet showed bluish pustules

Old healed scars were seen over all 4 limbs.

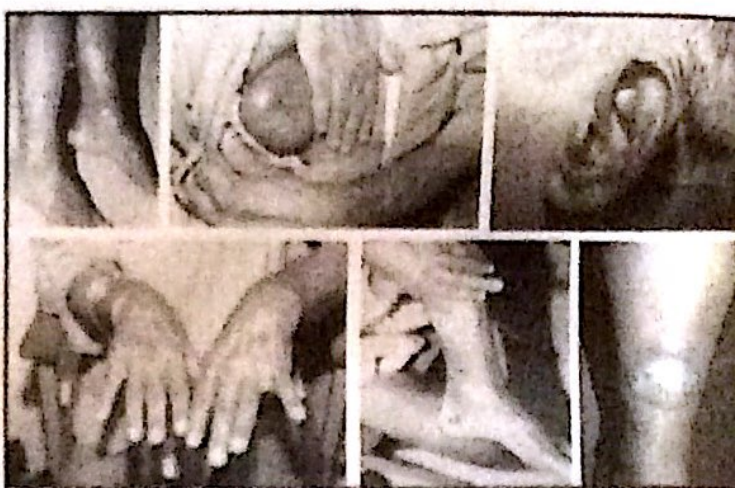

Figure 4: $\quad A=$ Old healed scars over both lower limbs Uteers over the scrotum, $\mathrm{C}=$ Nodules ove pinna, $\mathrm{D}=$ Scars and ulcers over both han $=$ New pustules over ankle. $F=$ Healing over shin of leg)

\section{Biopsy findings}

Date12/3/004 from pustule (ankle) and ulcer (ell Epidermis spongiosis

Dermis- suppurative abscess at upper det associated with abundant neuclear dust neutrophils, many neutrophils, many lymphoc: a few plasma cells, a few macrophages. follic structures not seen.

\section{Date $27 / 7 / 004$ from pustule knee}

A nodular dermal infiltrate rich in neutrophi association with perivascular lymphoc infiltrates. Many arrector pili muscles remnant not associated with neighbouring follicles. 
epidermis unremarkable.

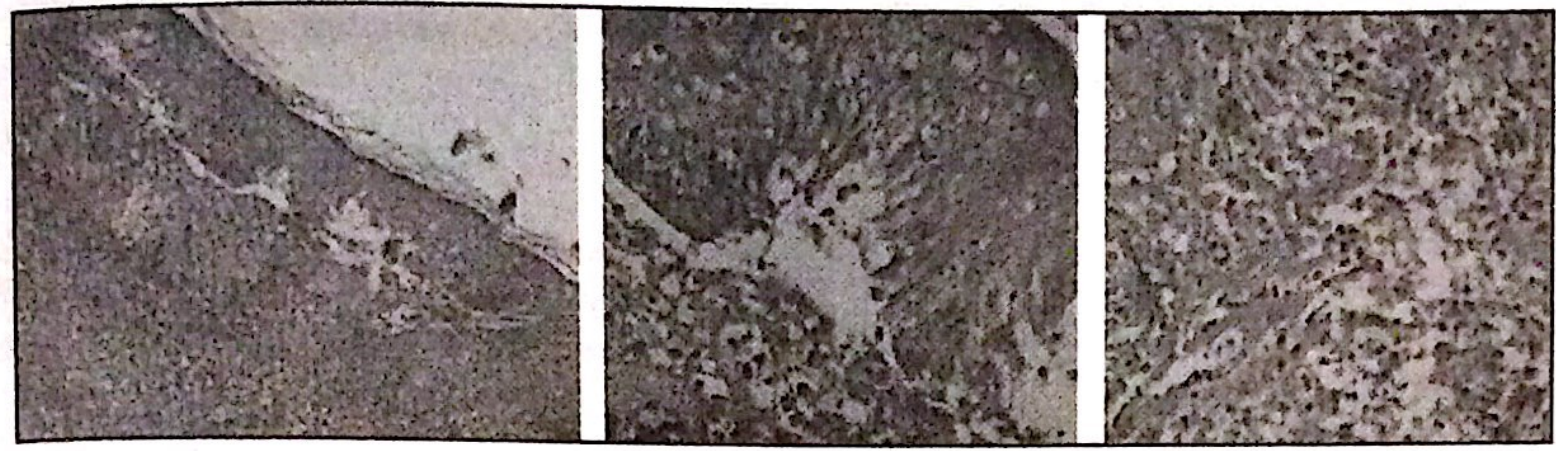

Figure 5: $(A=$ Photomicrograph showing diffuse and nodular dermatitis with many neutrophils with lysis of superficial dermis, $B=$ Magnified view of $A$ showing intra epi-dermal neutrophils, $C=$ Neuclear dusts, the neutrophils and lymphocytes at the superficial dermis)

\section{Drug response}

As the disease belongs to neutrophilic disease spectrum, minocycline, dapsone, colchicine, zinc sulphate were first tried along with analgesics and topical antibiotic. Lesions remained progressively growing, then it was treated with $1 \mathrm{gm}$ methylprednisolone IV once a day for 5 days, topical steroid as creams and local infiltration.

Drug response was dramatic, all lesions started healing, and tenderness disappeared. patient was discharged with Sulphasalazine tab $2 \mathrm{gm}$. once a day for 30 days.

One month later the patient was again readmitted for appearance of new ulcers associated with oozing, crusting, bleeding, bluish and blackish necrotic areas and oedema over both legs.

He was treated with 2 nd pulse of methyl prednisolone, oral analgesic and proton pump inhibitor which showed slight improvement.

Clofazimine $100 \mathrm{mg}$ three times a day was started followed by Cyclosporin $500 \mathrm{mg}$ once a day.

After 1 month the lesions subsided. Cyclosporin was reduced to $200 \mathrm{mg}$ but within the next 3 days new lesions started appearing, so again it was raised to $500 \mathrm{mg}$ once a day and $200 \mathrm{mg}$ Clofazimine once a day.

Cyclosporin was started on 2nd August till Nov 14, so administered for around 100 days, with much improvement but in view of its side effects like loss of appetite, diarrhoea, headache which developed in our patient, it was discontinued.

Presently, the patient is on Clofazimine $100 \mathrm{gm}$ twice a day, Cyproheptadine, Prantoprazole, topical
Clobetasole and Silversulfadiazine. So, far, his lesions remain subsided.

\section{Discussion}

The objective of this study is to identify Pyoderma gangrenosum as a possible cause of this condition and recommend appropriate treatment accordingly. Punch biopsy from ulcer (elbow) pustule (ankle) did not show follicular remnants supporting suppurative folliculitis as initiating event.

PG is fundamentally not a vasculitis but a suppurative folliculitis. Some authors believe it as primary vasculitis.

This condition has been described in literature available till date as occurring in $50 \%$ patients as an idiopathic condition and $50 \%$ as a systemic disease.

Abnormalities of humoral, cell mediated immunity, complement, neutrophil, monocyte function were noticed by others.

Defective neutrophil chemotaxis and neutrophil phagocytosis have also been reported.

It has been suggested that deposition of immune reactants in dermal vessel walls may be important in pathogenesis of diseases.

Spectrum of drugs used to treat this condition is wide. Immunosuppresants like Cyclosporine, Azathioprine and neutrophil phagocytic enhancers like Clofazimine are used.

Cyclosporine acts preferably on $\mathrm{T}$ cells probably by limiting production of Interleukin 2 and in 
particular by preventing precursor TH cells from acquiring ability to respond to IL 2 . This inhibit proliferation and maturation of TS cells.

The course and prognosis of this condition is chronic and progressive.

\section{Conclusion}

Our case study clearly illustrates that pulse steroid therapy is beneficial.

Continued need for suppression of inflammatory process following pulse therapy by use of Combination of clofazimine, cyclosporin and topical agents are required.

\section{References}

1. Cutaneous vascular disease Amold,H.L.,Odom,R.B.andJames,W.D 'Andrews' Diseases of the skin ed;1990.p.986-8. W.B. Saunders Company

2. Pyoderma Gangrenosum. Histologic diagn of inflammatory skin diseases 2nd ed; $\mathrm{p}$ e 677, A Bernard Ackerman 1997. William Wilkins

3. R.K. Curley, R.K., Macfarlane A.W. \& Vic G.F.H. Pyoderma gangrenosum treated, cyclosporin. British Journal of Dermatol Nov 1985. Vol. 113 No. 5. $601-04$. 